\title{
Experimental Study and Analysis of Slurry Erosion Wear of SS304L Material
}

\author{
K. M. Nilkar, A. S. Runwal, N. S. Bhole, P. R. Jagtap, B. D. Nandre \\ (Department of Mechanical Engineering, M.E.S.College of Engineering, S.P.Pune University*, India)
}

\begin{abstract}
A slurry erosion wear problem occurs generally in transportation of solid liquid mixtures, pumps, hydro turbines, petroleum extraction well. In this project we are going to conduct experiment on erosion wear at normal impact angles using a slurry pot tester for SS304L. In case of ductile material maximum wear is found when angle of impact is approximately $30^{\circ}$ and for brittle material angle of impact is normal to the surface. Experiments will be conducted by changing solid concentrations, velocity and particle size. Based on the experimental study, relation between erosion rate and normal impact angle is to be predicted. The main objective is to study the effect of kinetic energy on different size solid particles after impact on same target material by using Ansys software.
\end{abstract}

Keywords: Impacting angle, Particle size, Pot tester, Slurry pot tester, SS304L.

\section{Introduction}

Wear is defined as removal and deformation of material on surface causing volume loss of material. It may occur due to corrosion, abrasion or erosion. The reason for corrosion wear is chemical reaction, which can be prevented by accepting suitable methods; where abrasion and erosion wear can minimized by controlling the affecting parameters. The economy of hydraulic conveyance of solids is directly affected by slurry transportation systems, so in selection and design of slurry transportation system erosion wear is important parameter. Erosion wear reduces service life of equipments and therefore from past few decades prediction of the erosion loss of materials is necessary. Erosion wear depends on large number of parameters. It is necessary to reduce the erosion wear to improve the service life of the equipments used in handling of solid liquid mixture. Investigators investigated dependence of erosion wear on various parameters. Small bench scale test rigs is widely used to generate large number of data at an accelerated rate. The wear characteristics of target materials have been broadly classified as ductile and brittle type[1].In 20th century, when number of slurry transportation systems came into existence slurry erosion has gained importance during that period. Service life of components is reduced due to erosion wear. Petroleum extraction wells, coal liquefaction processes, solids handling systems, hydraulic turbines are affected by slurry erosion wear. It is therefore necessary to find out the slurry erosion wear for design and selection of any solid-liquid handling system. Various methods used to find out erosion wear are pilot loop plant test, field test and bench scale tests[2]. Efforts have also been made by many investigators to understand the mechanism of erosion wear. However, the goal of design engineers is to estimate the erosion wear for a combination of impacting solid particles and target components. Hence a large number of experimental data is generally collected using a bench scale test rig to develop an empirical correlation for calculate the wear. It can be observed from these data, show large variations due to use of different test rigs, materials and test conditions, and therefore no universally accepted correlation exists[1].

\section{Literature Review}

Desale, et al.[1] carried experiments to simulate erosion wear due to solid-liquid mixture on design of pot tester. A pot tester is used to study the relation between different impacting materials and solid concentration. In pot tester there is problem with uniform distribution of solids and turbulence inside the pot pot tester and hence there are limited application for quantitative analysis. In investigations transparent cylindrical pot to find out the minimum speed of a propeller required for uniform distribution of solid particals . These observations are used to develop a slurry pot tester. The results were obtained for ductile target material.Nandre, et al.[2] developed a pot tester to simulate the erosion wear due to solid-liquid mixture. A pot tester was used to study the relative erosion behaviour of different material at moderate solid concentration, velocity, and particle size and impact angle. A pot tester was then fabricated by inserting propeller from the bottom of the cylinder. Then it was rotated at the speed required for uniform distribution. The test specimens were then mounted at different shaft inserted from the top of the pot and was rotated at desired speeds. The results were obtained for ductile material.More, et al.[3] studied the effect of impacting particle kinetic energy on the slurry erosion wear. The slurry pot tester was used to conduct the experiments. In this investigation same sized impacting particles of 
qurtz, $\mathrm{SiC}$, alumina were used. Copper was used as target material. It was seen that material removal from the target surface affected by kinetic energy and stress concentration factor of impacting particles. At $90^{\circ}$ orientation angle, mass loss for the same mean particle size is nearly constant but variation is found in $30^{\circ}$ orientation angle. The experiment shows that the material removal mechanism is a function of erodents shape.Desale, et al.[4] have studied ductile materials behaviour on the effect of erodent properties on erosion wear. Experiments are carried out in a pot tester to calculate the wear of two ductile materials, AA6063 and AISI SS304L steel. Mixtures of similar particle sizes of three different natural erodent's namely, quartz, alumina and silicon carbide have used to calculate the mass loss of the two target materials at different impact angles. Shape factor for erodent was determined. which showed decreasing value for increase in angularity of the particle. As the wear increases with decrease in the shape factor and increase in the density.Desale, et al.[5] have studied the slurry erosion of aluminium alloy (AA 6063) by varying particle size. The slurry pot tester is used for investigation. Quartz particles with eight different sizes (varying between 37.5 and $655 \mu \mathrm{m}$ ) have been used. The velocity of specimen was $3 \mathrm{~m} / \mathrm{s}$ with orientation angle of $30^{\circ}$ and $90^{\circ}$ in a sand-water mixture of $20 \%$ concentration (by weight). As particle size increases, the erosion wear also increases. The two different mechanisms were noticed for mean particle size above $200 \mu \mathrm{m}$. Change in the wear rate at a particular particle size occurs at some threshold kinetic energy of impacting particle. Relation between threshold kinetic energy for different operating condition and the change in erosion mechanism is discussed.Neilson, et al.[6] have studied the erosion by a stream of solid particles. In their work, the effects of particles shape, particles velocity and angle of impact were observed and the parameters affecting particles deposition in the specimen surface are enumerated. A simple approach to a theoretical analysis of the problem was given and the relationships derived were used to correlate the experimental results. To determine the erosion-angle attack characteristics these relations are used.Hawthorne, et al.[7] have studied single particle-target surface interactions along with target material in the Coriolis slurry erosion tester. The Coriolis test is used for calculating the slurry erosion behavior of materials. The results assure previous theoretical predictions that in the Coriolis test mode erodent particles interact with the specimen in a series of low angle impacts of decreasing angle, also it affects rebound height and normal velocity component along the specimen. Hawthorne, et al.[8] have designed a new slurry erosion tester. It improved slurry dynamics. The slurry tester provided a relation between the resistance of different materials to slurry erosion damage under low intensity conditions. Control of the slurry flow on test specimen surfaces is given by new design of rotor assembly. Wear patterns on tester components is similar to that of calculated. The effects that the less turbulent fluid flow has affect on slurry erosion, as measured by specific energy or by parameters erosion resistance. The new tester is more efficient in sensitivity than earlier designs of specimen holders, or specimen positioning inserts, It depends upon machining tolerances.Gandhi, et al.[9] have examined Nominal particle size of multi-sized particle slurries for calculation of erosion wear and effect of fine particles. Selection and design of slurry transportation systems erosion wear at the wetted passages is a critical parameter for erosion wear. Erosion wear is a complex theory and is difficult to determine for multi-sized particles slurries mostly depend on a single particle size. Nominal particle size of multi-sized particles are required for mass loss due to the erosion wear.Desale, et al.[10] have studied the slurry erosion of aluminium alloy (AA 6063) by varying particle size. The slurry pot tester is used for investigation. Quartz particles with eight different sizes (varying between 37.5 and $655 \mu \mathrm{m}$ ) have been used

The velocity of specimen was $3 \mathrm{~m} / \mathrm{s}$ with orientation angle of $30^{\circ}$ and $90^{\circ}$ in a sand-water mixture of $20 \%$ concentration (by weight). As particle size increases, the erosion wear also increases. The two different mechanisms were noticed for mean particle size above $200 \mu \mathrm{m}$. Change in the wear rate at a particular particle size occurs at some threshold kinetic energy of impacting particle . Relation between threshold kinetic energy for different operating condition and the change in erosion mechanism is discussed. JHA, et.al[11] have studied the effect of rotating speed and impinging angle for aluminum. Commercial aluminum (grade 1900) was exposed to slurry sand in water in rotary motion at various angles. Mass loss was measured for calculation of wear. From results it is found that wear rates increase with increasing impingement angle up to $90^{\circ}$. Maximum wear rate occurs at $90^{\circ}$, which is contrary to the conventional understanding of maximum loss of ductile material takes place at about $45^{\circ}$ impingement angles. As rotation speed of samples increases ,the wear rate also increases exponentially. Khairnar, et al.[12] simulated the erosion wear of AISI SS304L. A jet tester was used to study the erosion behavior of different material by changing solid concentration, velocity, and particle size and impact angle. . Then a pot tester was fabricated. Test fixture was fixed and has a provision to move in different angular position to find out the wear. Due to the impact of high velocity of slurry erosion of materials was occurred which came out from the nozzle and impacting on the test specimen. During experiments angle is vary from $15^{\circ}$ to $90^{\circ}$ in six intervals of $15^{\circ}$ difference, particle size is 655 micron and $10 \%$ solid concentration for 120 minutes. Lynn, et. al.[13] studied the slurry erosion by changing particle size. They used the erosion pot tester rig. At constant speed of $18.7 \mathrm{~m} \mathrm{~s}^{-1}$ the erosion rates of cylindrical steel specimens tested in the pot tester using $1.2 \mathrm{wt} \%$ concentration of $\mathrm{SiC}$ in oil for particle diameters between 20 and $500 \mu \mathrm{m}$ were determined. The function of particle size is the rate of particle impact on unit surface area. The impact velocity values from a 
suspension flow are compared with kinetic energy of particle. For constant solid loading, proportion of solid particle decreases, particle size decreases erosion rate decreases, impact velocity decreases. Clark, et al.[14] studied the effects of specimen diameter, impact velocity, and erosion rate, particle density in a slurry pot erosion tester. It uses the technique of measuring impact crater size, stagnation line impact velocities of glass spheres. Similarly, the change in normal impact velocity is the function of angular location about the target material has measured. Erosion rates for 1020HR steel specimens in the diameter range $3.2 \mathrm{~mm}$ to $9.1 \mathrm{~mm}$ is determined. It uses 1.2 wt. \% suspension in diesel oil of silicon carbide particles, mean size $136 \mu \mathrm{m}$. Impact velocity measured for spherical particle ranges from density between $2420 \mathrm{~kg} \mathrm{~m}^{-3} \& 7830 \mathrm{~kg} \mathrm{~m}^{-3}$ suspended in diesel oil. The changes in impact conditions and erosion rates studied using a model of suspension flow, particle impact on target.

\section{Figures And Table}

Fig. 1 shows variation of erosion wear with impact angle for ductile and brittle material [3]. Fig. 2 shows the schematic diagram of the slurry pot tester with dimensional details. Figs. 3,4,5,6, and 7 shows dimensional details of various parts of slurry pot tester [All dimensions are in $\mathrm{mm}][2]$.

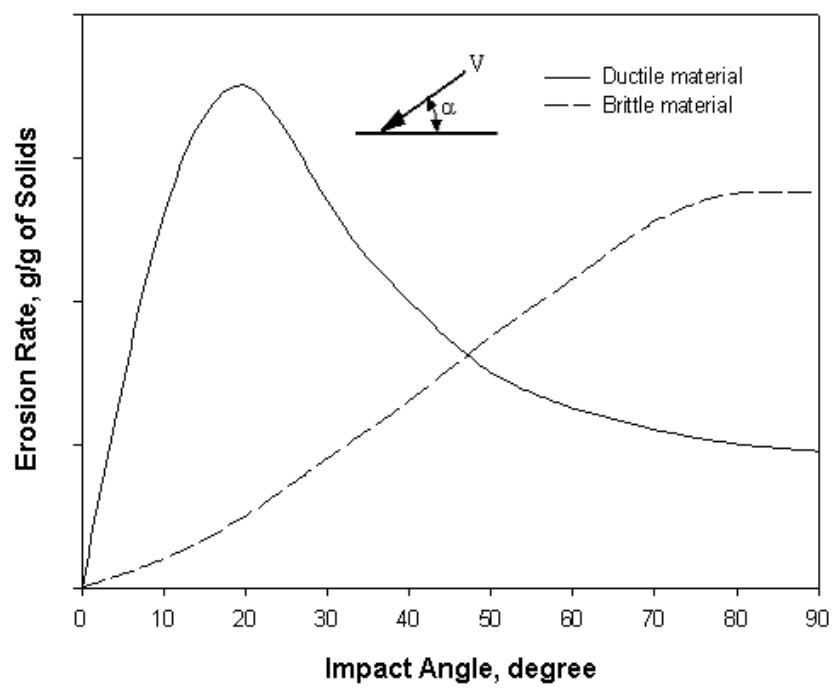

Fig.1: Variation of erosion wear with impact angle[3].

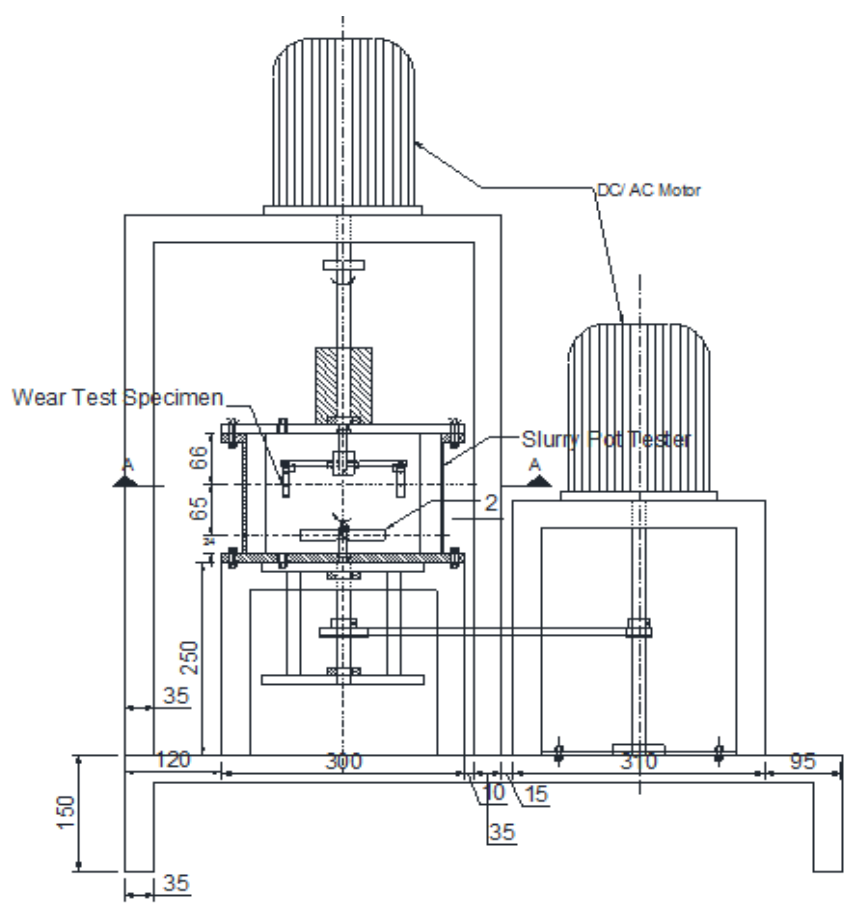

Fig. 2: Slurry pot tester setup[2]. 

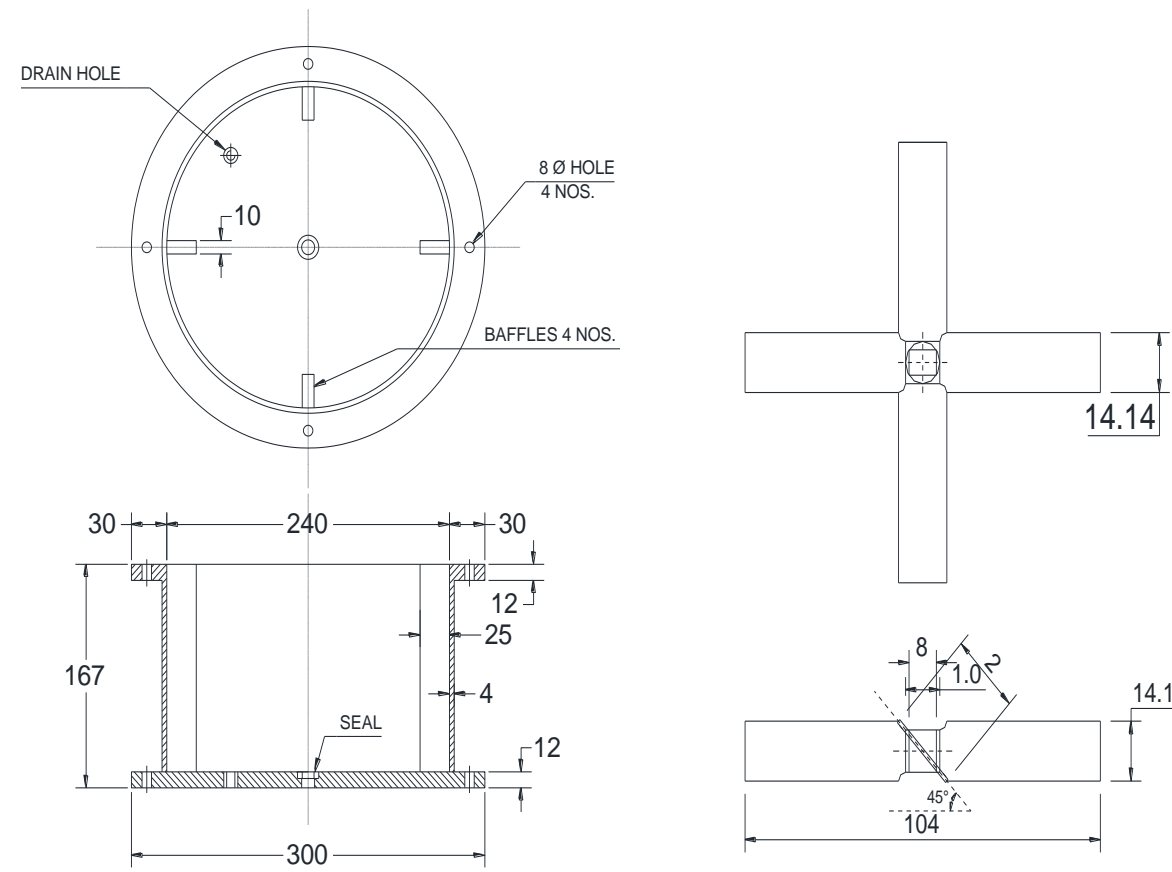

Fig.3: Details of slurry pot[2].

Fig. 4: Details of four bladed $45^{\circ}$ pitched blade turbine (PBT-4) propeller[2].

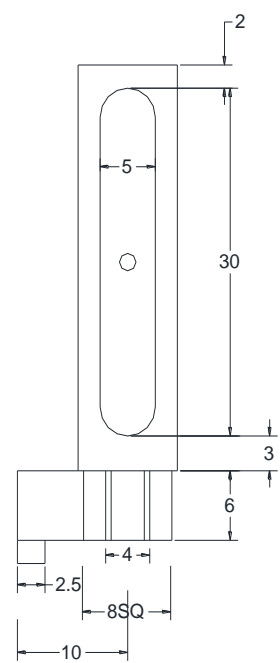

Fig. 5: Test Fixture[2]

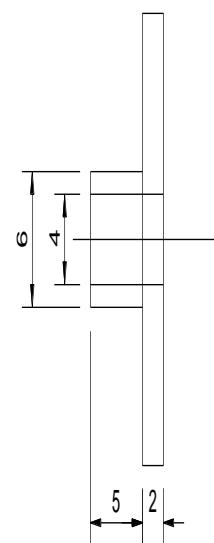

Fig. 6: Indexing plate[2].

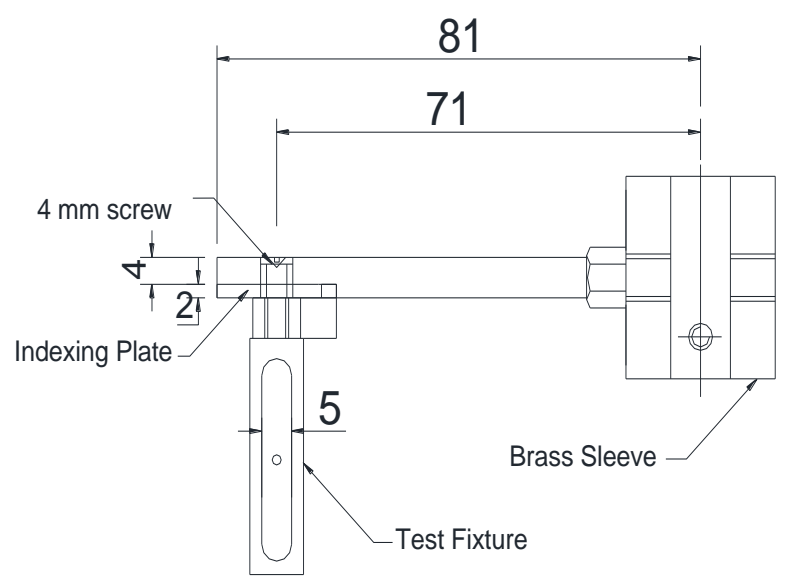

Fig. 7: Fixing arrangement for test fixture[2]. 
fig. 1: Composition of elements of target material[2].

\begin{tabular}{|c|c|c|c|c|c|c|c|c|c|c|}
\hline Sr.No. & Target Material & \multicolumn{8}{|c|}{ Elemental composition (wt. \%) } \\
\hline & & $\mathrm{C}$ & $\mathrm{Mn}$ & $\mathrm{P}$ & $\mathrm{S}$ & $\mathrm{Si}$ & $\mathrm{Cr}$ & $\mathrm{Ni}$ & $\mathrm{Mo}$ & $\mathrm{N}$ \\
\hline 1 & AISI SS304L & 0.030 & 2.00 & 0.045 & 0.030 & 0.75 & $17.50-9.50$ & $8-12$ & - & 0.10 \\
\hline
\end{tabular}

Table. 2: Physical properties of erodents[3].

\begin{tabular}{|c|c|c|c|c|c|}
\hline Solid particle & $\begin{array}{c}\text { Chemical } \\
\text { Formula }\end{array}$ & Colour & $\begin{array}{c}\text { Specific gravity } \\
\left(\mathrm{kg} / \mathrm{m}^{3}\right)\end{array}$ & $\begin{array}{c}\text { Particle } \\
\text { shape }\end{array}$ \\
\hline Quartz (IS sand) & $\mathrm{SiO}_{2}$ & Whitish & 2652 & 1100 & Blocky \\
\hline Silicon carbide & $\mathrm{SiC}$ & Blackish & 3210 & 2500 & Sub-angular \\
\hline Alumina & $\mathrm{Al}_{2} \mathrm{O}_{3}$ & Brown & 3970 & 1800 & Angular \\
\hline
\end{tabular}

\section{Conclusion}

In this paper, experimental and numerical investigation of different researchers from previous work on slurry erosion has been reviewed. The generic conclusions drawn from the literature survey are summarized as under.

- A pot tester of 7.21 liter capacity developed by Desale et al. used to predict the slurry erosion wear.

- There is provision to orient the wear specimens at different orientation angle in slurry pot tester.

- Experiments were conducted to find out the slurry erosion characteristics of different target materials.

- The erosion wear is calculated for various solid-liquid mixture of different erodent particles with tap water at different impact angles shows typical ductile erosion behavior for the selected materials.

- The mass loss due to erosion is function of kinetic energy.

\section{Acknowledgement}

The authors are gratefully acknowledge the financial support from BCUD SPPU PUNE.

\section{References}

[1]. G. R. Desale, Bhupendra K. Gandhi, S.C. Jain, Improvement in The Design of a Pot Tester to Simulate Erosion Wear due to Solid-Liquid Mixture, International Journal on the Science and Technology of Friction Lubrication and Wear, 259, 2005,196-202.

[2]. S. R More, B.D Nandre, G R Desale, Development of Pot Tester to Simulate the Erosion Wear due to Solid-Liquid Mixture, International Journal of Researchers,2,2014, 6-12.

[3]. Satish R More, Bhushan D Nandre, G R Desale, S H Gawande,Effect of impacting particle kinetic energy on slurry erosion wear, Springer International Publishing AG, 2015,1-9.

[4]. G. R. Desale, Bhupendra K. Gandhi, S.C. Jain, Effect of Erodent Properties on Erosion Wear of Ductile Type Materials, International Journal on the Science and Technology of Friction Lubrication and Wear,261, 2006,914-921.

[5]. G. R. Desale, Bhupendra K. Gandhi, S.C. Jain,Particle Size Effects on The Slurry Erosion of Aluminium Alloy (AA 6063), International Journal on the Science and Technology of Friction Lubrication and Wear, 266, 2009,1066-1071.

[6]. J.H. Neilson and A. Gilchrist, Erosion by Stream of Solid Particles, International Journal on The Science and Technology of Friction Lubrication and Wear, 1967,111-122.

[7]. H.M. Hawthorne, Y. Xie, S.K. Yick,A Study of Single Particle-Target Surface Interactions along a Specimen in the Coriolis Slurry Erosion Tester, International Journal on the Science and Technology of Friction Lubrication and Wear,253, 2002,403-410.

[8]. H.M. Hawthorne, Y. Xie, S.K. Yick, A New Coriolis Slurry Erosion Tester For Improved Slurry Dynamics, International Journal on the Science and Technology of Friction Lubrication and Wear, 255, 2003,170-180.

[9]. Bhupendra K. Gandhi, Satish V. Borse, Nominal Particle Size of Multi-Sized Particulate Slurries For Evaluation of Erosion Wear and Effect of Fine Particles, International Journal on the Science and Technology of Friction Lubrication and Wear, Volume 257, 2004, pp. 73-79.

[10]. Girish R. Desale, Bhupendra K. Gandhi, S.C. Jain, Particle Size Effects on The Slurry Erosion of Aluminium Alloy (AA 6063), International Journal on the Science and Technology of Friction Lubrication and Wear,266, 2009, 1066-1071.

[11]. A. K. JHA, R. Batham, M. Ahmed, A.K. Mujumdar, O.P.Modi, S. Chaturvedi, A.K. Gupta. Effect of Impinging Angle and Rotating Speed on Erosion Behaviour of Aluminium, Transactions of Nonferrous Metals Society of China, volume 21, 2011,32-38.

[12]. Hitesh S. Khairnar, Pramod A. Thakur, Dr. E.R. Deore, S.R. More, Simulate the Erosion Wear of AISI SS 304L due to Solid-Liquid Mixture, IORD Journal of Science and Technology,2, 2015,49-55. 
[13]. Randall S. Lynn, Kein K. Wong, Hector McI. Clark,On the Particle Size Effect in Slurry Erosion, International Journal on the Science and Technology of Friction Lubrication and Wear,149, 1991,55-71.

[14]. Hector McI. Clark,Specimen Diameter, Impact Velocity, Erosion Rate and Density in a Slurry Pot Erosion Tester, International Journal on the Science and Technology of Friction Lubrication and Wear, 162-164,1993,669-678. 